\title{
Colonization of Host Plants by the Fire Blight Pathogen Erwinia amylovora Marked with Genes for Bioluminescence and Fluorescence
}

\author{
Jochen Bogs, Iris Bruchmüller, Claudia Erbar, and Klaus Geider
}

First, second, and fourth authors: Max-Planck-Institut für Zellbiologie, Rosenhof, D-68526 Ladenburg, Germany; and third author: Institut für Systematische Botanik und Pflanzengeographie, Universität Heidelberg, Im Neuenheimer Feld 345, D-69120 Heidelberg, Germany. Accepted for publication 17 January 1998.

\section{ABSTRACT}

Bogs, J., Bruchmüller, I., Erbar, C., and Geider, K. 1998. Colonization of host plants by the fire blight pathogen Erwinia amylovora marked with genes for bioluminescence and fluorescence. Phytopathology 88:416-421.

To follow the movement of Erwinia amylovora in plant tissue without dissection, this bacterium was marked with either the lux operon from Vibrio fischeri or the $g f p$ gene from the jellyfish Aequorea victoria, both carried on multicopy plasmids and expressed under the control of the lac promoter from Escherichia coli. Movement of the pathogen was visualized in leaves, stems, and roots of apple seedlings, and migration of $E$. amylovora was traced from inoculation sites in the stem to as far as the roots. Green fluorescent E. amylovora cells were observed in the xylem and later appeared to break out of the vessels into the intercellular spaces of the adjacent parenchyma. Inoculation in the intercostal region of leaves caused a zone of slow necrosis that finally resulted in bacterial invasion of the xylem vessels. Labeled bacteria could also be seen in association with the anchor sites of leaf hairs. Distortion of the epidermis adjacent to leaf hairs created openings that were observed by scanning electron microscopy. As the intercostal region, the bases of leaf hairs provided E. amylovora access to intact xylem vessels, which allowed further distribution of the pathogen in the host plant.

Additional keywords: green fluorescent protein, luciferase, root colonization.
Fire blight of apple and pear trees and other rosaceous plants is caused by the gram-negative bacterium Erwinia amylovora $(31,32)$. The disease is spread by insects, birds, wind, and human activities. Flowers are the dominant target for natural infections of host plants and show symptoms of progressive necrosis. Depending on the plant parts affected, the disease has been named blossom, shoot, fruit, limb/trunk, or collar/root blight. Entry sites are assumed to be provided by nectaries, stomata, and other natural openings on the plant surface. To follow the path of bacteria within the host, nondisruptive markers such as bioluminescence and fluorescence provide a suitable tool for detection. Use of the lux operon from Vibrio fischeri for tracing pathogenic bacteria in plants (25) or on plant surfaces (24) has been described for Xanthomonas campestris. When the genes in the lux operon are efficiently expressed, luciferase and reductase are the key enzymes required for bioluminescence. The intensity of bioluminescence is strongly dependent on the cellular level of ATP to recycle tetradecanal, the luciferin for light production. In principle, it is possible to see single cells with the use of charge coupled device-enhanced microscopy (26). However, motile bacteria or those with low metabolic activity cannot be detected by this device. The use of the fluorescent protein GFP (green fluorescent protein) of Aequorea victoria, which can be expressed in both eukaryotic and prokaryotic cells (5), can circumvent this limitation. GFP is a 238 -amino acid protein that depends on UV light and oxygen for green fluorescence. GFPtagged bacteria can be studied in plants without disruption of the tissue or fixation of the bacterial cells. Even single cells can be traced and their association with host cells studied. Recently, the

Corresponding author: K. Geider; E-mail address: kgeider@zellbio.mpg.de

Publication no. P-1998-0226-01R

(C) 1998 The American Phytopathological Society
GFP system was used to visualize early events in nodulation of alfalfa by Rhizobium meliloti (12).

Numerous studies have been done to elucidate migration of $E$. amylovora in plant tissue. Often, plants were inoculated by damaging the vascular system, and bacterial spread in the xylem was observed $(27,28)$. The phloem was also assumed to provide a path for movement of E. amylovora (17). When the bacteria are applied to succulent shoots of the susceptible rootstock M26, they predominantly colonize the cortical parenchyma $(1,7)$. After natural blossom infections, bacterial movement occurs mainly in the intercellular spaces, but they may also migrate in the xylem after wound infection (32).

In this study, we used in situ detection techniques to follow the colonization of the fire blight pathogen in plant tissue, its movement through the xylem into the parenchyma, and its progression into the root system. Of particular interest was the association of bacteria with leaf hairs that can give rise to a rupture of the surrounding epidermis, which may provide an entry site for E. amylovora to invade the xylem. Parts of this report were presented in the Proceedings of the Seventh International Workshop on Fire Blight (3).

\section{MATERIALS AND METHODS}

Strains and plasmids. E. amylovora strains Ea7/74 and Ea1/79 $(10,11)$ and the nonpathogenic ams mutant Ea1/79-D50 (amsD::Tn5) (4) were described previously. The multicopy plasmid pfdC1 was derived from DNA fragments with replication functions of bacteriophage fd $(13,14)$. The lux operon from $V$. fischeri was excised from plasmid pUCD605 (25) as a SalI fragment and inserted into plasmid pfdC1Z', which contains the lac $Z^{\prime}$ linker and the lac promoter from pUC18. The resulting plasmid, pfdC1Z'-lux, was transformed by electroporation (19) into E. amylovora and was stably propagated in contrast to ColE1 or RP4 plasmids. However, light 
production was initially unstable. The consumption of ATP for bioluminescence apparently stressed the bacterial cells, and this may have selected for loss of the plasmid or for inactivation of the lux operon. Passaging the freshly transformed cells several times on nutrient agar with kanamycin $(\mathrm{Km}, 20 \mu \mathrm{g} / \mathrm{ml})$ and screening single colonies for light production yielded variants with stable bioluminescence, which were used for the inoculation experiments. The plasmid pfdC1Z'-lux has been previously used to detect the spread of E. amylovora on lawns of pear cells (11).

Plasmid pBGS18-gfp was constructed by cloning a BamHI DNA fragment from pSET8 (R. Sprengel, Heidelberg, Germany) into pBGS18. Properties of GFP are described elsewhere (5). A DNA fragment with an optimized $g f p$ gene was transferred from $\mathrm{pGFPm} 1$ (6) via pFG30 (provided by F. Gong, Ohio State University, Columbus) into plasmid pfdC1Z', yielding pfdC1Z'-gfp. The bacteria were grown at $28^{\circ} \mathrm{C}$ in Luria-Bertani broth (LB) that was supplemented with $1 \%$ sorbitol (LBS).

Plant material. For growth of apple seedlings, seeds were stratified for 5 days in ice water, germinated for 2 to 4 weeks at $10^{\circ} \mathrm{C}$, and then transferred into soil. The plantlets were illuminated in a growth chamber for $16 \mathrm{~h}$ at $22^{\circ} \mathrm{C}$ and allowed to grow further for at least 3 weeks.

Inoculation of plant tissue and detection of bioluminescence and fluorescence. Strain Ea7/74(pfdC1Z'-lux) was grown on Standard I agar (E. Merck AG, Darmstadt, Germany) plates with $\mathrm{Km}$ $(20 \mu \mathrm{g} / \mathrm{ml})$. Bioluminescence of LBS broth cultures was determined in the BioOrbit Luminometer 1250 (Wallace Oy, Turku, Finland). A hypodermic needle was dipped into bacterial colonies on agar and used to inoculate stems of apple seedlings (cv. Golden Delicious). After 2 or more days of incubation at $22^{\circ} \mathrm{C}$, the inoculated plants were pressed on an X-ray film (Kodak X-Omat; Eastman Kodak Co., Rochester, NY) in a cassette and exposed for $2 \mathrm{~h}$ or over night. Similarly, strains Ea7/74(pBGS18-gfp) or Ea1/79(pfdC1Z'gfp) were used for inoculation of young leaves (about 1 week old) of apple seedlings. The experiments were performed with three leaves of at least three plantlets. The most reliable inoculation $(>90 \%)$ was achieved when the leaves were punctured at the end of the petiole with a hypodermic needle or the leaf tips were cut with scissors that were either dipped into colonies on agar or into an undiluted overnight bacterial culture, and then the plantlets were covered with plastic bags after inoculation. Diluted bacterial cultures were less efficient, but still produced signals when applied to leaves at $5 \times 10^{6} \mathrm{CFU} / \mathrm{ml}$ with disruptive methods. To avoid damage of plant tissue, the bacteria were also applied directly as droplets or on soaked filter paper disks to the lower side of leaves. This method did not always create a good infection, and bacterial movement was often found to be retarded. For visualization of weak to intermediate bacterial fluorescence (pBGS18-gfp), leaf tissue was treated with $70 \%$ acetone for $8 \mathrm{~min}$ to reduce autofluorescence of plant tissue. The specimen was washed in tap water and mounted on a glass slide in either $86 \%$ glycerol or tap water. The samples were examined with a Zeiss Axiovert fluorescence microscope (type 405M or 135; Carl Zeiss, Inc., Oberkochen, Germany) with the filter combination BP450-490/FT510/LP520 (excitation filterdichroic-emission filter).

Examination of leaf samples with confocal and scanning electron microscopy. Leaf samples were mounted in glycerol and visualized with a 100 per numerical aperature 1.3 oil immersion objective in a Zeiss IM35 inverted microscope equipped with the Argon ion laser Omnichrome (Carl Zeiss, Inc.) and a confocal laser scanning modul (Leica Lasertechnik, Heidelberg, Germany). For scanning electron microscopy (SEM), pieces of leaves from apple seedlings were fixed in FAA $(5 \mathrm{ml}$ of formalin, $5 \mathrm{ml}$ of acetic acid, and $56 \mathrm{ml}$ of $96 \%$ ethanol) for at least 3 days. For examination, the samples were dehydrated in formaldehyde dimethylacetale (dimethoxymethane), critical point-dried using liquid $\mathrm{CO}_{2}$, and then further processed for SEM (SEM Leitz AMR 1200B; Leitz $\mathrm{GmbH}$, Wetzler, Germany) as described elsewhere (8).

\section{RESULTS}

Dependence of bioluminescence on the stage of growth. A broth culture of E. amylovora strain Ea7/74(pfdC1Z'-lux) in LBS medium was measured for bioluminescence and cell density for $13 \mathrm{~h}$ (Fig. 1). Light production increased with bacterial growth until they reached mid-log phase. After $7 \mathrm{~h}$, a strong decline in bioluminescence was observed that continued during further incubation, although the cell density still increased. This finding suggests that only actively growing cells in log phase can provide sufficient ATP for the lux reductase to recycle the luciferin.

Movement of $E$. amylovora from the stem into the root. Apple seedlings were stem-inoculated about $3 \mathrm{~cm}$ above the root with a needle dipped into a colony of strain Ea7/74(pfdC1Z'-lux). After 3 days, the seedlings were exposed to X-ray film (Fig. 2). Very little spread of the bacteria was observed above the inoculation site, whereas a strong zone of light extended downward into the roots. In more than 10 experiments, bioluminescence resided mainly in the upper root part, but was never observed in the entire root. A continuous line of bioluminescence from the inoculation site into the root clearly showed movement inside the stem, suggesting that bacteria rapidly gained access to at least part of the root system.

Labeling $\boldsymbol{E}$. amylovora with GFP. To determine the precise location of E. amylovora in plant tissue, we labeled the cells with the gene for GFP from A. victoria. When plasmid pBGS18-gfp was transferred into E. amylovora strain Ea1/79, most of the cells exhibited typical green fluorescence under UV light. We observed a gradual loss of the pBGS18-gfp plasmid and, therefore, assayed several other plasmid replicons for their stability in E. amylovora without antibiotic selection. Plasmids with the replication origins of p15 (mini 15), pSC101, RSF1010, or bacteriophage fd were stable, although inserted DNA fragments that expressed the $g f p$ gene decreased stability. Plasmids with ori-fd and fd gene 2 have high copy numbers (14) and were barely lost from the host cells, even when carrying reporter genes. The expression of the $g f p$ gene was significantly better from pfd plasmids than from plasmids with an intermediate copy number and ColE1 plasmids. Since

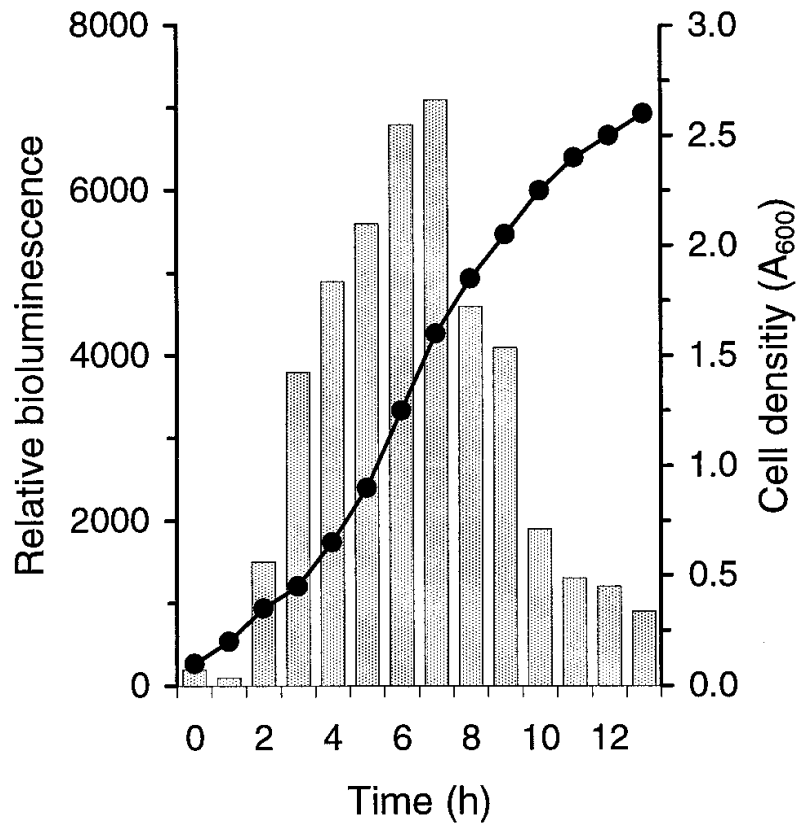

Fig. 1. Bioluminescence and cell density. Strain Ea7/74(pfdC1Z'-lux) was grown overnight in Luria-Bertani broth supplemented with 1\% sorbitol and kanamycin. An aliquot was diluted 1:100 in fresh medium, and $100 \mu \mathrm{l}$ was measured for bioluminescence at various times (bars). The cell density (line) was determined by turbidity. 
GFP requires folding and additional processing steps to display fluorescence, the signal may not be seen in the entire cell population, and individual cells may differ in intensity. In the case of Ea1/79(pBGS18-gfp), fluorescence of individual cells was intermediate. The bright fluorescence of Ea1/79(pfdC1Z'-gfp) was also uniform. Nonfluorescent cells were rarely observed.

Localization of $\boldsymbol{E}$. amylovora in plant tissue by fluorescence microscopy. Young leaves from 3-week-old apple seedlings were inoculated with strain Ea1/79 carrying pBGS18-gfp or pfdC1Z'gfp by wounding an intercostal leaf area with a hypodermic needle or by cutting leaf tips with scissors (Fig. 3A and B). Four to five days after inoculation, these leaves were detached, and small pieces taken from the inoculation site to about $2 \mathrm{~cm}$ away were examined with the fluorescence microscope. Inoculation of the intercostal region resulted in a slowly expanding necrotic zone. The fluorescent bacteria in this zone were mainly located in the parenchyma, but bacteria also moved from the intact parenchyma into the xylem vessels (Fig. 3A). In 2 out of 10 assays, the bacteria entered the vascular system, whereas, in other experiments, the pathogen was confined to the necrotic lesion. Bacteria were only observed in typical xylem vessels and not in the phloem, as shown by the moderate fluorescence of strain Ea1/79(pBGS18-gfp) in Figure 3B. Parts of the vessels were completely filled with bacteria, others had a low number of fluorescent bacteria, and there were also xylem areas without bacteria.

Bacterial movement in the vascular system was also achieved by cutting the leaf tip. After an initial delay, Ea1/79(pfdC1Z'-gfp) migrated approximately $2 \mathrm{~cm}$ through the middle vein over a period of 4 days, but did not move into the parenchyma adjacent to the inoculation site. The bacteria could be easily observed in the

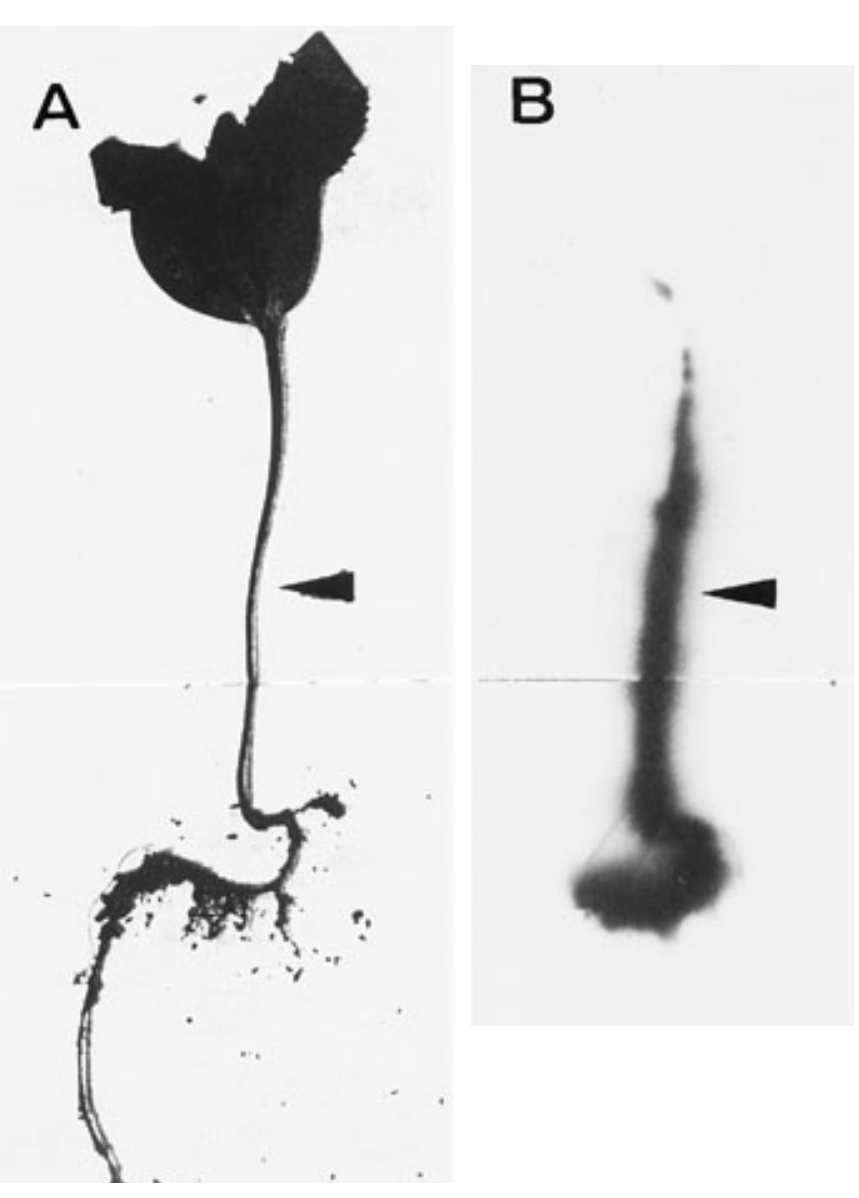

Fig. 2. Invasion of Erwinia amylovora into the root system. An 8-week-old apple seedling was inoculated with a needle dipped in a culture of Ea7/74(pfdC1Z'-lux) and further grown in soil for 3 days. The inoculation site is marked by an arrow. A, Whole plant; and $\mathbf{B}$, bioluminescence. vessels because of the strong fluorescence of these cells (Fig. 4A) and were seen to progress to distal parts of the leaf during further incubation. The nonpathogenic ams mutant Ea1/79-D50(pfdC1Z'-gfp) did not move at all from the site of inoculation.

E. amylovora cells had a tendency to break out of the xylem vessels and enter the intercellular spaces of the surrounding parenchyma (Fig. 4). Tracing the xylem of an inoculated leaf at 5 days after incubation, we observed up to three outbreaks per centimeter behind the front of vascular migration. In heavily colonized vessels, the disruptions were more frequent than in freshly colonized vascular regions. After disruption of the xylem, the bacteria moved into the parenchyma, where a wedge-shaped area was formed by ejection of the bacterial cells from the pressurized vessels (Fig. 4C and D). At sites of outbreak from the xylem, the adjacent intercellular space became filled with fluorescent bacteria. Border pits, which have a diameter up to $4 \mu \mathrm{m}$, are weak structures in the xylem wall and could provide extrusion sites. The fluorescence label of E. amylovora cells was also seen in the intercellular spaces after partial maceration of leaf sections (data not shown).

Detection of bacteria in the outer root system. To localize $E$. amylovora in the root more precisely than was possible with bioluminescence, roots were sectioned 5 days after the stems were inoculated with a hypodermic needle. Examination of cross-sections revealed accumulation of fluorescent bacteria in xylem (data not shown). In other sections, the bacteria appeared adjacent to the Casparyan strip inside collapsed plant cells. Since fluorescent bacteria were found in all parts of the root, we conclude that their movement was not confined to the upper part of the primary root.

Entry of $E$. amylovora from anchoring sites of leaf hairs. Reliable means of inoculating with E. amylovora is often difficult
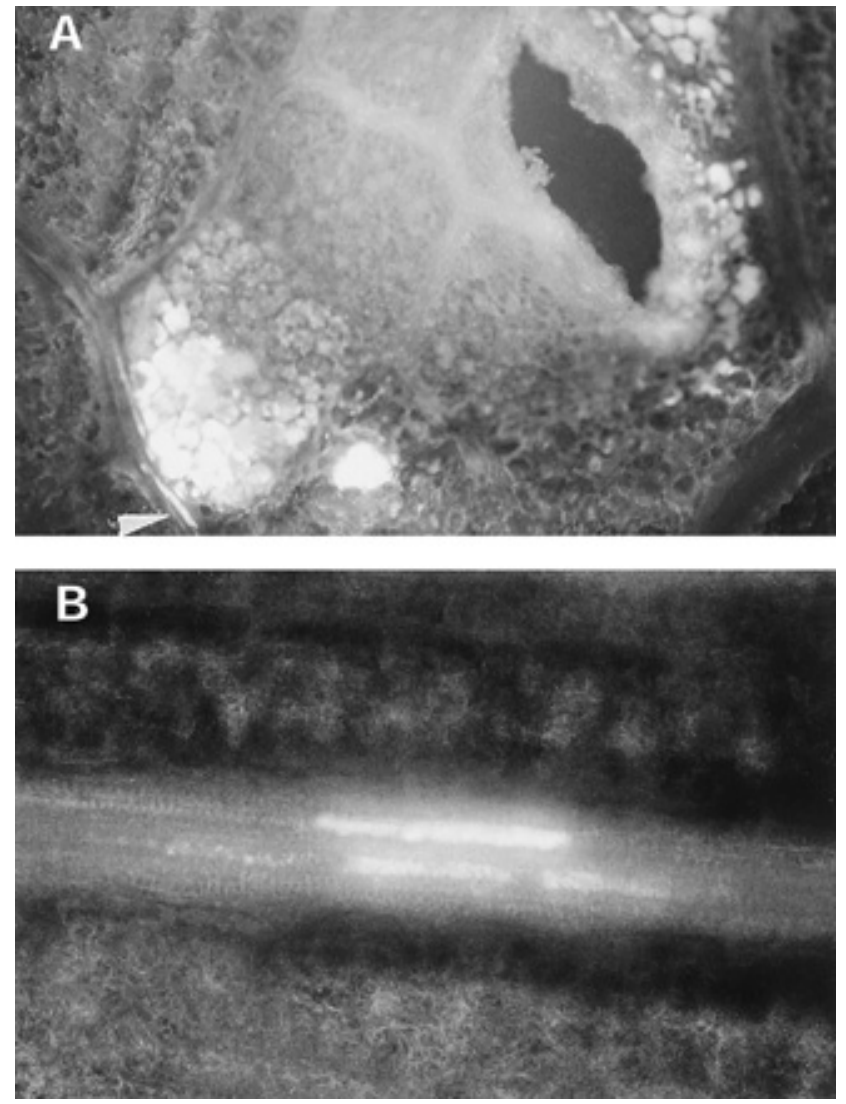

Fig. 3. Migration of Erwinia amylovora in leaves. A, Strain Ea1/79(pfdC1Z'lux) was inoculated by puncturing the intercostal region with a needle. The zone of damage by inoculation is seen as a black area and fluorescent bacteria are seen as a white zone. Their appearance in the vascular bundles is marked by an arrow. Magnification: $\times 60$. B, An apple seedling was inoculated with strain Ea1/79(pBGS18-gfp) by puncturing the central leaf vein with a needle. This leaf section was treated with $70 \%$ acetone. Magnification: $\times 380$. 
without damaging plant tissue. Inoculation of plants with a needle or cutting leaves with scissors heavily damage the plant tissue, and this was blamed for direct introduction of E. amylovora into the xylem system (32). A nondisruptive method was the application of diluted bacterial cultures directly onto the lower leaf epidermis as $10-\mu l$ droplets or small soaked filter paper disks. Many gfp-labeled E. amylovora cells then became associated with leaf hairs. To locate the position of E. amylovora precisely, we used a confocal microscope. With this imaging technique, leaf hairs with fluorescent bacteria were located in sequential layers by focusing the laser beam. The bacterial signals appeared in a layer, which was outside of the leaf hair. The bright bacterial fluorescence could be clearly distinguished from the faint fluorescence of the plant cell walls, with both signals in different layers.

In addition to the attachment of E. amylovora to leaf hairs, fluorescent bacteria accumulated along the anchor region of the hairs in the epidermis (Fig. 5A). Association of bacteria at the bases of foliar trichomes was common in the inoculated area and was seen in 1 to $10 \%$ of all leaf hairs. Some leaf hairs were partially filled with air bubbles and were assumed to be dead trichomes (21), which can easily break and, with a lever action, disrupt the surrounding epidermis. We visualized leaf hairs near the central vein by SEM (Fig. 6A). The foot section of the leaf hairs was intact in most specimens examined (Fig. 6B). Bacteria were often visible at the leaf surface after fixation of the plant tissue. About $5 \%$ of the foliar trichomes were damaged, displayed a hole at the anchor region, and were surrounded by bacteria (Fig. 6C). Consequently, bacterial cells accumulated at the anchoring sites of leaf hairs (Fig. 5), and these areas appeared to provide entry sites for pathogen invasion, because fluorescent bacteria were also seen in the adjacent vascular system (Fig. 5B). Even though foliar trichomes originate from epidermal cells and do not have linkage to the vessels, E. amylovora was apparently able to move from the foot region of a leaf hair through the intact cell layers around the xylem.

\section{DISCUSSION}

Fire blight is noticed when massive symptoms such as ooze or necrosis are visible on host plants. Migration of E. amylovora was first assumed to occur in the phloem (17), although later reports by Goodman et al. confined bacterial movement exclusively to the xylem after artificial inoculation involving damage of the main vein $(15,28)$. By using reporter systems, we localized bacteria in the xylem, found migration against the direction of the water flow, and observed bacterial aggregation to cause a disruption of the vessel walls, presumably at the pit membranes, which are sensitive to changes in the vessel pressure (9). Plugging of the vascular water system by bacteria and capsular extracellular polysaccharide could partially explain wilting symptoms associated with fire blight, because large polymers can cause a disruption of the water flow in the xylem (30).

The release of bacteria from the xylem and subsequent plasmolysis of parenchyma cells was previously documented by electron microscopy (16). Only areas adjacent to the inoculation site were found to be infested with bacteria (28). Our experiments demonstrate that bacteria can colonize the intercellular spaces of the parenchyma after disrupting the xylem vessels. Movement of $E$. amylovora from the xylem into the parenchyma was not restricted to the site of wounding, as described by Suhayda and Goodman (27). Migration in the xylem might exceed the speed of movement in the intercellular spaces and could be important for rapid colonization of plant tissue by E. amylovora. The xylem sap is not de-
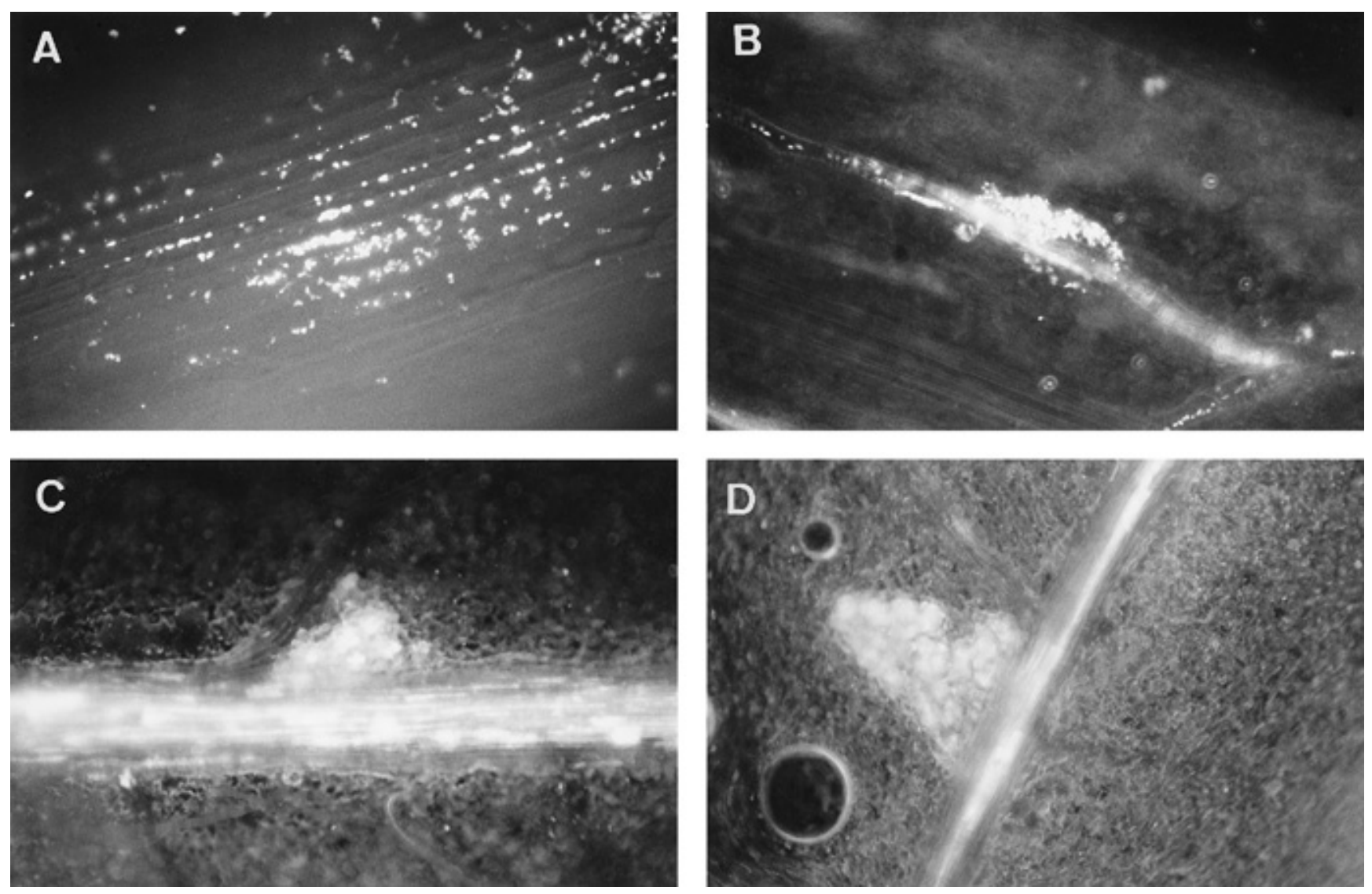

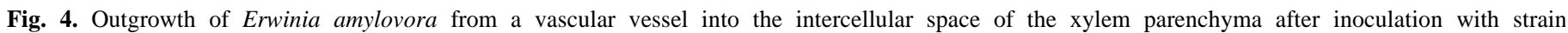

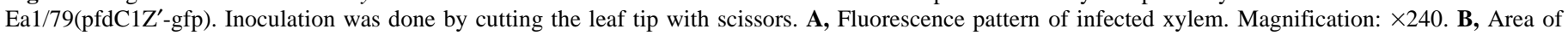

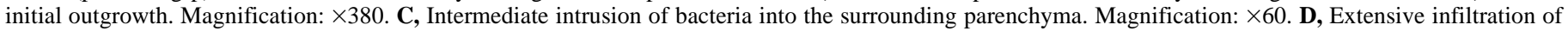
the surrounding parenchyma. Magnification: $\times 60$. 
void of nutrients and contains organic acids including the amino acids glutamine and asparagine (22). These were described before as attractants for E. amylovora (23) and may help the pathogen to find its way into the vessels. The level of asparagine in xylem sap is similar to the concentration used in the minimal media used for growth of E. amylovora and amylovoran production (2). In the vessels, the bacteria are minimally exposed to the plant defense mechanisms because of their rapid migration and the lignified walls of the xylem cells. On the other hand, outbreaks of bacteria into the parenchyma could provide a mechanism for intensive colonization and destruction of the plant tissue, thereby enhancing the formation of fire blight symptoms.

When inoculated into the stem, bacteria migrated to the roots. The lack of bioluminescence in distal parts of the root might indicate a low level of nutrients or other unfavorable conditions for light production in the lateral roots. However, using GFP as a reporter, we were able to detect bacteria in side roots, indicating that the entire root system can be colonized by the pathogen. Root blight has been occasionally reported to occur in field situations $(31,32)$. However, primary colonization of roots is probably not an important route of entry, and there is no evidence that E. amylovora can persist in soil. Moreover, when we inoculated roots, the bacteria did not readily migrate from the root into the stem section (I. Bruchmüller and K. Geider, unpublished data). Instead, they had a preference to move in the xylem against the water stream.

The colonization of the surface of pear leaves by Pseudomonas syringae pv. syringae has been followed by SEM, and bacterial entry sites were assumed to be at the base of trichomes and fissures in the cuticular layer (18). Epiphytic growth of E. amylovora has been previously shown to occur mainly around the stigma of blossoms (20). In the moist environment of apple shoot cultures,
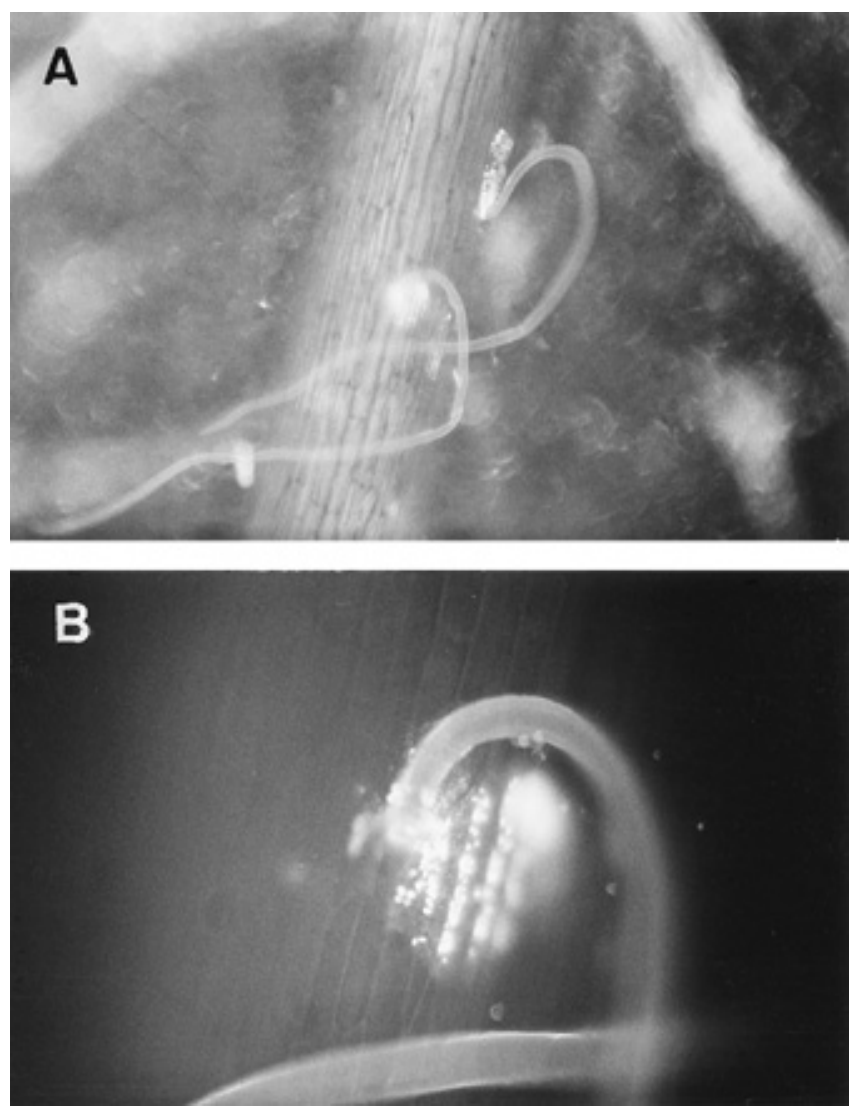

Fig. 5. Association of Ea1/79(pfdC1Z'-gfp) with leaf hairs and migration into the xylem. From a suspension culture, $10 \mu \mathrm{l}$ containing $5 \times 10^{5} \mathrm{CFU}$ was applied to the lower epidermis of a leaf and allowed to dry. A, Leaf section at application site of bacteria. Magnification: $\times 38$. B, Close-up of area with anchor site of leaf hair and the adjacent xylem. Magnification: $\times 60$. we observed spread along the surface of stems (data not shown). An entry site for the pathogen was found at the foot of leaf hairs. Leaf hairs are anchored in the epidermis (29) and may have several roles in fire blight infections. (i) They can shelter bacteria by providing a rough leaf surface. (ii) They increase humidity (18), and rapid movement of the bacteria has been seen on the moist surface of pear cell lawns (11). (iii) Leaf hairs can easily break, which results in temporary distortion of the epidermis (21), and bacterial cells seem to quickly take advantage of this situation and colonize the anchor site in the epidermis. (iv) The location of leaf hairs along the veins adjacent to the xylem provides a convenient access to the vessels. The attractants from the vascular bundles may stimulate the taxis of E. amylovora to the xylem, and the negative hydraulic pressure of the xylem should facilitate pathogen invasion.
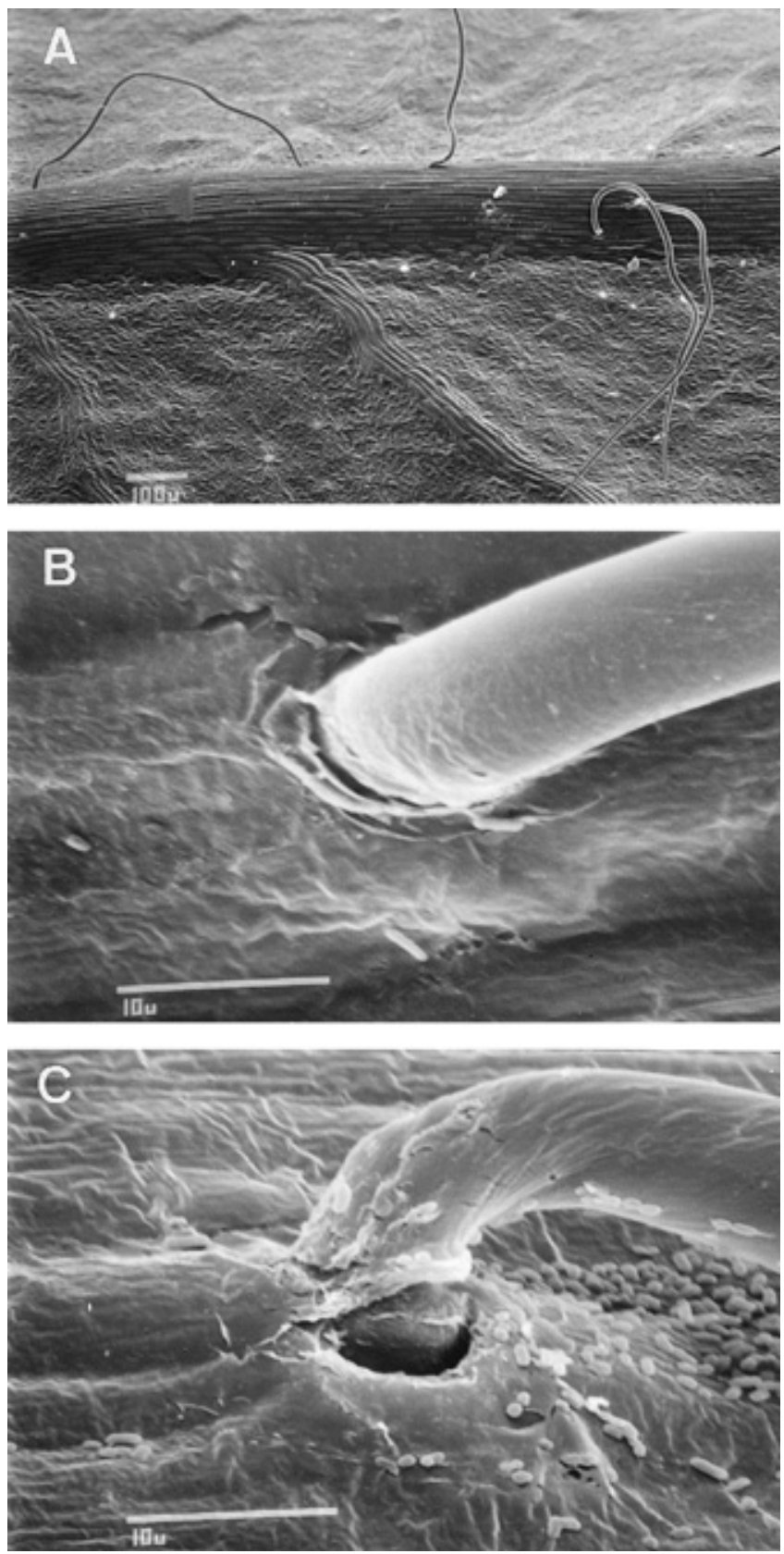

Fig. 6. Visualization of leaf hairs and the surrounding epidermis by scanning electron microscopy. A, Leaf area at low magnification. B, Foot area of leaf hair. $\mathbf{C}$, Same as $\mathbf{B}$, but with bacteria and a gap in the epidermis around the foot of a leaf hair. This was observed for approximately $5 \%$ of the examined leaf hairs. 
Blossoms are considered to provide the main entry site for fire blight infections $(31,32)$. In addition to leaves, flowers and stems also contain trichomes. All of these plant parts may become exposed to E. amylovora when contaminated insects visit these sites or when "strands" of bacterial ooze are carried from lesions to other parts of the same plant or to adjacent plants. The dominant routes of infection involved in fire blight epidemics depend on many conditions such as cultivar susceptibility, plant age, and weather. Leaf hairs or intercostal regions may not be the most frequent entry site, but they have been shown to provide a model for the invasion of host plant tissue and subsequent colonization of undamaged xylem vessels. Furthermore, the data presented have shown the usefulness of the lux system of $V$. fischeri and of the $g f p$ gene from jellyfish to trace bacterial movement within host plants. Bioluminescence was suitable to visualize populations of growing bacteria, whereas the GFP was also well suited to detect low numbers of marked E. amylovora cells by fluorescence microscopy.

\section{ACKNOWLEDGMENTS}

We thank H. Sawitzky and R. Hartig (Max-Planck-Institut, Ladenburg, Germany) for experiments with the confocal microscope and K. Naumann, Aschersleben, Germany, and S. Eden-Green, Kent, United Kingdom, for comments on the manuscript.

\section{LITERATURE CITED}

1. Bachmann, F. M. 1913. The migration of Bacillus amylovorus in the host tissues. Phytopathology 3:3-13.

2. Bellemann, P., Bereswill, S., Berger, S., and Geider, K. 1994. Visualization of capsule formation by Erwinia amylovora and assays to determine amylovoran synthesis. Int. J. Biol. Macromol. 16:290-296.

3. Bereswill, S., Bruchmüller, I., and Geider, K. 1996. Interference of copper sulfate with growth of Erwinia amylovora and monitoring bacterial propagation in planta. Acta Hortic. 411:191-196.

4. Bugert, P., and Geider, K. 1995. Molecular analysis of the ams-operon required for exopolysaccharide synthesis of Erwinia amylovora. Mol. Microbiol. 15:917-933.

5. Chalfie, M., Tu, Y., Euskirchen, G., Ward, W. W., and Prasher, D. C. 1994. Green fluorescent protein as a marker for gene expression. Science 263:802-805

6. Cormack, B. P., Valdivia, R. H., and Falkow, S. 1996. FACS-optimized mutants of the green fluorescent protein (GFP). Gene 173:33-38.

7. Eden-Green, S. J. 1972. Studies in fireblight disease of apple, pear and hawthorn (Erwinia amylovora (Burill) Winslow et al.). Ph.D. thesis. University of London.

8. Erbar, C., and Leins, P. 1989. On the early floral developement and the mechanisms of secondary pollen presentation in Campanula, Jasione and Lobelia. Bot. Jahrb. Syst. Pflanzengesch. Pflanzengeogr. 111:29-55.

9. Esau, K. 1965. Plant Anatomy. J. Wiley \& Sons, Inc., New York.

10. Falkenstein, H., Bellemann, P., Walter, S., Zeller, W., and Geider, K. 1988. Identification of Erwinia amylovora, the fireblight pathogen, by colony hybridization with DNA from plasmid pEA29. Appl. Environ. Microbiol. 54:2798-2802.

11. Falkenstein, H., Zeller, W., and Geider, K. 1989. The 29 kb plasmid, common in strains of Erwinia amylovora, modulates development of fireblight symptoms. J. Gen. Microbiol. 135:2643-2650.

12. Gage, D. J., Bobo, T., and Long, S. R. 1996. Use of green fluorescent protein to visualize the early events of symbiosis between Rhizobium meliloti and alfalfa (Medicago sativa). J. Bacteriol. 178:7159-7166.

13. Geider, K., Baldes, R., Bellemann, P., Metzger, M., and Schwartz, T. 1995. Mutual adaptation of bacteriophage fd, pfd plasmids and their host strains. Microbiol. Res. 150:337-346.

14. Geider, K., Hohmeyer, C., Haas, R., and Meyer, T. F. 1985. A plasmid cloning system utilizing replication functions of the filamentous bacteriophage fd. Gene 33:341-349.

15. Goodman, R. N., Huang, J. S., and Huang, P. Y. 1974. Host specific phytotoxic polysaccharide from apple tissue infected by Erwinia amylovora. Science 183:1081-1082.

16. Goodman, R. N., and White, J. A. 1981. Xylem parenchyma plasmolysis and vessel wall disorientation caused by Erwinia amylovora. Phytopathology 71:844-852.

17. Lewis, S., and Goodman, R. N. 1965. Mode of penetration and movement of fire blight bacteria in apple leaf and stem tissue. Phytopathology 55:719-723.

18. Mansvelt, E. L., and Hattingh, M. J. 1987. Scanning electron microscopy of colonization of pear leaves by Pseudomonas syringae pv. syringae. Can. J. Bot. 65:2517-2522.

19. Metzger, M., Bellemann, P., Schwartz, T., and Geider, K. 1992. Sitedirected and transposon-mediated mutagenesis with pfd-plasmids by electroporation of Erwinia amylovora and Escherichia coli cells. Nucleic Acids Res. 20:2265-2270.

20. Miller, T. D., and Schroth, M. N. 1972. Monitoring the epiphytic population of Erwinia amylovora on pear with a selective medium. Phytopathology 62:1175-1182.

21. Netolitzky, F. 1932. Die Pflanzenhaare. In: Handbuch der Pflanzenanatomie. Vol. IV, 2a. Gebr. Borntraeger, Berlin.

22. Purcell, A. H., and Hopkins, D. L. 1996. Fastidious xylem-limited bacterial plant pathogens. Annu. Rev. Phytopathol. 34:131-151.

23. Raymundo, A. K., and Ries, S. M. 1980. Chemotaxis of Erwinia amylovora. Phytopathology 70:1066-1069.

24. Shaw, J. J., Geiger, D. F., and Kloepper, J. W. 1992. Use of bioluminescence for detection of genetically engineered microorganisms released into the environment. Appl. Environ. Microbiol. 58:267-273.

25. Shaw, J. J., and Kado, C. I. 1986. Development of a Vibrio bioluminescence gene-set to monitor phytopathogenic bacteria during the ongoing disease process in a non-disruptive manner. Bio/Technology 4:560-564.

26. Silcock, D. J., Waterhouse, R. N., Glover, L. A., Prosser, J. I., and Killham, K. 1992. Detection of a single genetically modified bacterial cell in soil by using charge coupled device-enhancer microscopy. Appl. Environ. Microbiol. 58:2444-2448.

27. Suhayda, C. G., and Goodman, R. N. 1981. Infection courts and systemic movement of ${ }^{32} \mathrm{P}$-labeled Erwinia amylovora in apple petioles and stems. Phytopathology 71:656-660.

28. Suhayda, C. G., and Goodman, R. N. 1981. Early proliferation and migration and subsequent xylem occlusion by Erwinia amylovora and the fate of its extracellular polysaccharide (EPS) in apple shoots. Phytopathology 71:697-707.

29. Uphoff, J. C. Th., and Hummel, K. 1962. Plant hairs. In: Handbuch der Pflanzenanatomie. Vol. IV, 5. 2nd ed. K. Hummel and K. Staesche, eds. Gebr. Borntraeger, Berlin.

30. Van Alfen, N. K., and Allard-Turner, N. C. 1979. Susceptibility of plants to vascular disruption by macromolecules. Plant Physiol. 63:1072-1075.

31. Van der Zwet, T., and Keil, H. L. 1979. Fire blight: A bacterial disease of rosaceous plants. Agric. Handb. 510. U.S. Government Printing Office, Washington, DC.

32. Vanneste, J. L. 1995. Erwinia amylovora. Pages 21-41 in: Pathogenesis and Host Specificity in Plant Disease: Histopathological, Biochemical, Genetic and Molecular Bases. Vol. 1. Prokaryotes. U. S. Singh, R. P. Singh, and K. Kohmoto, eds. Pergamon Press, Oxford, London. 